ISSN $1515-7326, \mathrm{n}^{\circ} 14,1 \mid 2014$, pp. 113 a 144

\title{
Hechos, razones y acción colectiva: reflexiones en torno a la ontología social del derecho
}

\author{
Richard Ekins* \\ (Traducción del inglés de Natalia Scavuzzo)
}

Resumen: La realidad del derecho, aunque relacionada con la realidad social y la acción grupal, no puede ser reducida solo a esta última. Se propone una relectura de Austin y Hart y se expresan algunos desacuerdos con la teoría de Shapiro. En especial, el autor discute la importancia exagerada que el modelo de Shapiro da al problema de los alienados y no aceptantes.

Palabras clave: realidad social, acción conjunta, alienación.

Abstract: The reality of law, although related with social reality and joint action, cannot be reduced to them. This paper proposes a different way to tackle the question of the reality of law, including a different way to read Austin and Hart, and a main and general critique to Shapiro's theoretical frame regarding the relevance of alienation for a theory of law.

Key words: social reality, joint action, alienation.

\section{I}

Vale la pena explorar la hipótesis de que el derecho es una clase de acción colectiva. Es una realidad social, que consiste en hechos sociales sobre cómo las personas actuaron en el pasado y cómo lo harán en el futuro. Además, el derecho es sobre y para las personas, regula o dirige cómo estas deben actuar o lo que debe hacerse. Aun así, el derecho no es solo una realidad social, ya que cuando funciona bien - en el caso central - cambia las razones que los individuos

* St. John's College (Oxford, Reino Unido). 
tienen para actuar, cómo ellos deben actuar. Alguien puede describir el hecho social consistente en lo que ciertas personas piensan que deben o no hacer algo, incluyendo que piensan eso, en parte, por otro hecho social (por ejemplo el acto pasado de alguna autoridad jurídica); pero no se puede entender la naturaleza de la práctica del derecho hasta que no se piensa de la forma en que lo hace una persona dentro del sistema jurídico y se pregunta si el hecho social relevante (o conjunto de hechos) cambia en verdad lo que uno debería hacer, y cómo y por qué lo hace. La realidad del derecho debe encontrarse en las razones y en los hechos, lo que significa que la teoría del derecho debe esforzarse para explicar si (y cómo) los hechos sociales dan origen a razones para la acción.

Estos hechos sociales son el objeto del artículo de Bernal. En diálogo con Austin, Hart y Shapiro, Bernal considera la forma en que la práctica del derecho involucra a los funcionarios y, quizás, a sujetos (ciudadanos) que actúan en forma conjunta. Seguiré su camino, considerando y contribuyendo a su conversación con Austin, Hart y Shapiro, mientras discuto además las principales contribuciones de Aquino y otros, como el mismo Bernal lo hace. Creo justo decir que el propósito de Bernal es mostrar cómo la ontología social ilumina la naturaleza del derecho y, más específicamente, cómo los modernos estudios de la realidad social muestran a los trabajos de Austin y Hart como promesas frustradas. Además, en contraste, busca mostrar el poder del planteo de Shapiro (adecuadamente modificado y elaborado). Si bien comparto el interés de Bernal en explorar la forma en que el derecho consiste en la acción colectiva de un grupo (si es que lo es), no estoy completamente persuadido por el argumento del artículo. En lo que sigue explico mis inquietudes y brevemente delineo una alternativa. 


\section{II}

En la sección inicial de su artículo ${ }^{1}$, Bernal delinea el campo de la ontología social, que estudia la realidad social a la que nuestra acción colectiva da lugar. Señala los trabajos destacados de Bratman y Gilbert, entre otros, y el uso que se le ha dado a estos trabajos por los filósofos del derecho, incluyendo Kutz, Sanchez Brigido y especialmente Shapiro. La afirmación compartida por ellos según la cual el derecho está basado en una práctica social - lo que Bernal llama la tesis de la práctica social - no es, según Bernal, completamente novedosa, ya que ideas similares pueden encontrarse en el hábito de obediencia de Austin y en la atención que pone Hart en la aceptación de las reglas sociales ${ }^{2}$.

La forma en que Bernal da cuenta de la práctica social es deliberadamente amplia: requiere acciones intencionales colectivas recurrentes, donde esas acciones son ejecutadas por individuos que actúan como un grupo con las intenciones comunes ['we-intentions'] apropiadas, que son de conocimiento común ${ }^{3}$. Las acciones no consisten simplemente en la superposición de las intenciones y acciones individuales, que yo he llamado, siguiendo a Gilbert, teorías "sumatorias" de la acción colectiva ${ }^{4}$. Bernal también afirma que las acciones colectivas no son aquellas "de un agente colectivo que la lleva a cabo por su cuenta y con sus propias intenciones" 5 . Esta proposición no es clara. Infiero que su intención es evitar cualquier referencia a una mente misteriosa del grupo, que de alguna manera existe con independencia de las intenciones y acciones de las personas individuales. Quizá su preocupación sea, en cambio, excluir la acción de los agentes grupales que son grupos formados para actuar de manera coherente y racional a lo largo del tiempo sobre una serie de proposiciones interrelacionadas.

1 Bernal Pulido, C., "Austin, Hart, y Shapiro. Tres variaciones alrededor del derecho como una entidad fundada en una práctica social", Discusiones, XIV, 2014.

2 Bernal Pulido, C., op. cit., pág. 25

3 Bernal Pulido, C., op. cit., págs. 27.

${ }^{4}$ Ekins, R., The Nature of Legislative Intent, Oxford, Oxford UP, 2012, pág. 48.

5 Bernal Pulido, C., op. cit., pág. 26. 
Richard Ekins

E1 trabajo de Pettit y List sobre agencia grupal es, para mí, el desarrollo más interesante sobre ontología social ${ }^{6}$, ya que va más allá del argumento sobre la naturaleza precisa de las bases de la acción colectiva, incluyendo un estudio sobre sus complejidades e implicaciones. Bernal, al igual que Shapiro, no discute sobre agencia grupal y se centra, en cambio, en la acción colectiva simpliciter, sin atender a cómo o a si el grupo en cuestión está formado para actuar en una forma que evite la incoherencia o inconsistencia. Shapiro se aleja de Bratman en la medida en que prevé el caso de la alienación ${ }^{7}$ para los miembros del grupo que no llegan a tener un compromiso pleno con los fines del mismo. La alienación merece atención, así también como la deserción secreta y otros modos no centrales de participación en la acción colectiva ${ }^{8}$, pero también la merece la agencia grupal. ${ }^{9}$ Esta omisión es particularmente digna de resaltar en el contexto de la teoría del derecho, porque se debe considerar la posibilidad de que la ley que gobierna a las personas que forman un grupo de agentes sea, de alguna manera, producto del acto de un agente singular. De una forma más modesta, se debería al menos considerar la forma en que las instituciones jurídicas y políticas -tribunales, ministerios y legislaturas- forman agentes grupales ${ }^{10}$, disciplinados para actuar conjuntamente como una persona racional natural.

La acción colectiva de un agente grupal es similar a la acción colectiva de cualquier otro grupo con una intención, atento a que todos esos grupos son asociaciones con algún fin y con capacidad de actuar colectivamente debido a un conjunto de intenciones entrelazadas $^{11}$. Sin embargo, se diferencian fuertemente en la medida en que los miembros que buscan ejercer la agencia racional persiguen actuar colectivamente de una forma coherente y consistente, que cambia

6 List, C. y Pettit, P., Group Agency, Oxford, Oxford UP, 2011.

7 Shapiro, S., Legality, Cambridge, Harvard University Press, 2011, págs.14446, 150, 418-19.

8 Ekins, R., op. cit., págs. 65-66.

9 Ekins, R., op. cit., págs. 71-76.

${ }^{10}$ Considero la agencia de la legislatura en Ekins, R., op. cit., págs. 236-43.

$116 \quad{ }^{11}$ Ekins, R., op. cit., pág. 73. 
la forma en que ellos razonan y escogen. Si el objetivo del grupo es dar respuesta a razones complejas a lo largo del tiempo, existe una buena razón para que el grupo se estructure de esta manera. La acción compleja de introducir y mantener un sistema jurídico puede requerir dicha agencia, tanto a nivel general (por parte de la comunidad política) o en prácticas particulares de legislación y aplicación.

Señalé que para Bernal el trabajo reciente sobre ontología social del derecho tiene sus antecedentes en Austin y Hart. Considero, como en otra oportunidad ${ }^{12}$, que Bernal ha exagerado la novedad de las ideas sobre ontología social. Aquino vio con claridad la realidad social de los grupos y de la acción colectiva, incluyendo el modo en que un grupo es una especie de todo, aunque sea una unidad de orden y no de composición ${ }^{13}$. Esto significa que las personas individuales que forman 'parte' del grupo llevan a cabo acciones que conforman la acción del grupo, del todo, y otras acciones que no son parte de la acción del mismo en lo absoluto. Igualmente, el grupo puede hacer ciertas cosas que ninguna persona dentro de este puede hacer (por ejemplo, ganar la guerra). El orden que unifica a los muchos en un todo consiste en la coordinación entre los miembros del grupo; coordinación que está al servicio del propósito del mismo, el fin para el cual los miembros forman una asociación. El caso central de un grupo con una intención, único tipo de grupo capaz de actuar, es el de una asociación unida para un fin, en la que los miembros adoptan intenciones entrelazadas para alcanzarlo a través de determinados medios ${ }^{14}$. Los medios pueden ser muy generales y pueden hacerse estipulaciones para que algunos individuos adopten medios particulares. De este modo, vemos cómo el concepto de acción colectiva unánime incluye a la acción colectiva compleja y a los procedimientos de la autoridad ${ }^{15}$.

12 Bernal Pulido, C. op. cit.

${ }^{13}$ Aquino, Sententia Libri Ethicorum [Commentary on Aristotle's Nichomachean Ethics], prólogo de Finnis, J., Aquinas: Moral, Political and Legal Theory, Oxford, OPU, 1998, págs. 23-9.

${ }^{14}$ Ekins, R., op. cit., págs. 50, 64.

${ }^{15}$ Ekins, R., op. cit., págs. 57-60. 
En verdad, Aquino dijo poco sobre cómo, en general, los miembros de un grupo se coordinan para alcanzar un fin ${ }^{16}$. Pero vio con claridad que los grupos actúan colectivamente, que constituyen agentes de los que las personas individuales forman parte y que, aun así, son distinguibles de un todo. Este entendimiento conforma, entre otras cosas, su análisis del derecho y el gobierno. Se encuentra en Hobbes, Locke y Rousseau un interés similar por la realidad social de la comunidad política, a la que ellos entienden como un grupo, un todo formado de partes, personas, que actúan conjuntamente en el ejercicio de los poderes públicos. La contribución de la moderna ontología social es considerar con cuidado el patrón de intenciones que hacen inteligible nuestra acción colectiva ${ }^{17}$. En esta literatura, tanto como en Aquino, lo que caracteriza a la acción colectiva es que esta conecta a los miembros del grupo que comparten un propósito con la intención de actuar juntos para alcanzar un fin. La atención que Shapiro brinda a la alienación trata de diluir esta afirmación, argumentando que en la acción colectiva en gran escala es probable y posible que muchos no compartan el fin en cuestión. Esta psicología puede darseen casos tales como la deserción secreta y otras varias patologías. Pero esto no cambia la naturaleza de la acción colectiva, que es, en el caso bien formado, el caso central, de acuerdo con el cual los miembros del grupo llevan a cabo el plan que conjuntamente comparten en pos de alcanzar el fin para el que se creó. Los medios adoptados y el contenido del plan ponen en juego el fin propuesto, el cual se da en función de las intenciones de los miembros del grupo.

Bajo esta luz, vemos cómo para Aquino el caso central del derecho es una ordenación de la razón en la regla, promulgada por el bien común y adoptada por cada sujeto como si fuera propia ${ }^{18}$. El gobernante actúa para los miembros de la comunidad política (la ciudad, el reino, el imperio), que reconocen su autoridad para

${ }^{16}$ Finnis, J., "Prologue: Aquinas: Moral, Political and Legal Theory", en AQUINO (ed.), Sententia Libri Ethicorum (comentario a la Ética Nicomaquea de Aristóteles), Oxford, Oxford UP, 1998, págs. 27-8.

${ }^{17}$ Ekins, R., op. cit., pág. 64.

${ }^{18}$ Aquino, Summa Theologica, I-II q. 90 a. 4c. 
gobernar y acatan sus elecciones promulgadas al resolver qué es lo que todos tienen razón para hacer. El derecho de las personas libres, Aquino argumenta, es tanto un derecho que las personas hacen para sí mismas, una forma de costumbre, como un derecho elegido por un gobernante que representa a las personas libres y que actúa por su bien y en su nombre ${ }^{19}$. El derecho es, en este sentido, un acuerdo inteligente entre personas, entre los sujetos que forman la comunidad política y, entre los sujetos y el gobernante que actúa por el bien común ${ }^{20}$. El deber de cada persona de obedecer el derecho surge del bien común, que es el objeto de su asociación y del ejercicio del poder público. Incluso cuando las leyes particulares fallan para servir al bien común (y por ello son injustas), una obligación colateral, debida a los conciudadanos más que al gobernante, requiere de cierta obediencia ${ }^{21}$. Otra vez, aunque uno quisiera que Aquino hubiese dicho más sobre cómo se forma un pueblo y cómo actúa colectivamente, su teoría del derecho positivo está basada en la realidad social de la comunidad política y en la reciprocidad que se obtiene entre sus miembros, ya sean sujetos o gobernantes.

\section{III}

Para Bernal es posible interpretar que Austin desarrolla una versión de la tesis de la práctica social si se entiende al hábito de obediencia como una actividad intencional colectiva. Él sostiene que, prima facie, el hábito de obediencia puede entenderse como "una actividad que debe ejecutarse necesariamente por varios individuos"22; que no puede ser hecha por uno solo, pero sí por aquellos que conjuntamente constituyen la mayor parte de la sociedad; que esta mayoría no es un super-agente, es un grupo $^{23}$; y que los individuos cumplen los

\footnotetext{
${ }^{19}$ Aquino, Summa Theologica, I-II q. 97 a. 3 ad. 3; I-II q. 90 a. 3.

${ }^{20}$ Finnis, J., op. cit., págs. 256-8, 264-6.

${ }^{21}$ Finnis, J., Natural Law and Natural Rights, Oxford-New York, Clarendon Press-Oxford University Press, (2a ed.), 2011, págs. 361, 476.

22 Bernal Pulido, C., op. cit., pág. 29

${ }^{23}$ Ibid.
} 
requerimientos intencionalmente, ya que "llevan a cabo las acciones intencionalmente mediante el cumplimiento de [...] los mandatos del soberano, motivados por la amenaza de las sanciones"24. Sin embargo, Bernal nota dos problemas al seguir a Austin para explicar el derecho como una actividad intencional colectiva. Voy a considerar solo uno, según el cual "el hábito general de obediencia no es necesariamente una acción colectiva" ya que puede ser entendido tanto individual como colectivamente ${ }^{25}$. Si es lo primero, cada individuo tiene un hábito de obediencia personal, motivado por su auto-interés o miedo. En la segunda visión, los individuos actúan colectivamente obedeciendo al soberano. Bernal sugiere que no es claro cuál es la mejor lectura, pero entiende que la última visión se ve reforzada por el hecho de que para Austin el soberano debe ser un superior común ${ }^{26}$.

Entiendo que no hay una buena razón, en lo absoluto, para sostener la lectura colectiva. Austin hace que el grupo (la sociedad) surja a partir del hábito, antes que al hábito como formado y elegido por un grupo que existe independientemente del primero. Esto significa para Austin que el grupo es quienquiera tenga el hábito de obedecer a un soberano particular. Uno podría estar tentado de decir que el grupo consiste en quienes comparten un hábito, pero en verdad no hay nada compartido aquí, hay una simple superposición. Nada en la visión de Austin sugiere que los sujetos del derecho actúen conjuntamente o tengan una relación entre ellos más allá de ser súbditos del mismo soberano, la cual es una relación entre soberano y sujeto. En contraste, para Aquino hay una comunidad política con un bien común, para la que la autoridad es apropiadamente instituida y ejercida, y entre cuyos miembros hay una amistad y reciprocidad que hace posible y requiere de la acción colectiva.

El énfasis que Austin pone en la relación entre soberano y súbdito tiene eco en el caso Calvin ${ }^{27}$, en el que un escocés, súbdito de Jacobo VI de Escocia, debía ser considerado inglés ya que también era,

\author{
24 Ibídem. \\ ${ }^{25}$ Bernal Pulido, C., op. cit., pág. 30. \\ ${ }^{26}$ Bernal Pulido, C., op. cit., pág. 31. \\ $120 \quad{ }^{27}$ Calvin's Case (1608) 77 E.R. 377; 7 Co. Rep. 1a.
}


por esa razón, un súbdito de Jacobo I de Inglaterra. Sin embargo, en este caso la fidelidad a la persona del soberano da pertenencia a un ámbito (diferente), a un grupo que existe con independencia de la persona particular del soberano. Jacobo I no era Inglaterra; una sucesión de reyes, y de usurpadores también, tomaron su lugar en el trono de Inglaterra, que fue y es un grupo, un todo, del que el rey era la cabeza ${ }^{28}$. Para Austin, los sujetos del derecho no son un grupo que actúa, sino un grupo sobre el que se actúa, lo que implica decir que no son un grupo con propósito capaz de acción colectiva. Austin sostiene que cuando un soberano rival se levanta y algunos sujetos del derecho lo siguen, comienzan a existir - hasta la reunificación si la hay-dos sociedades ${ }^{29}$. Esto confirma que su teoría no tiene recursos para explicar cómo un grupo puede existir con independencia de un soberano particular, ni cómo ese grupo puede hacer del soberano lo que es: la subordinación, como él lo remarca, es pasiva e irreflexiva. Hay razones para pensar que Austin dio por sentado que los soberanos toman su lugar dentro de un grupo, como sugiere la forma en la que aborda el tema de la sucesión, según Hart ${ }^{30}$. Pero nada en esta teoría se aparta de la afirmación de que lo único que unifica es la subordinación al soberano. En efecto, la afirmación que en parte motiva el caso Calvin, a saber que Jacobo era rey de Inglaterra e, independientemente - a fuerza de un cargo diferente-, rey de Escocia, era ininteligible para Austin. Para este autor, más allá del nombre que Jacobo se haya dado a sí mismo, debió haber gobernado un solo grupo. Le desconcierta que los súbditos pertenecientes a ambos ámbitos reconozcan a cada ámbito como diferente, sin perjuicio de que la lealtad al rey diera derecho a la pertenencia al otro grupo.

Según Bernal, no hay razón para pensar que el acto relevante ejecutado de conformidad con las órdenes de un soberano austiniano

${ }^{28}$ Fortescue, J., In Praise of the Laws of England, chapter XII en Lockwood, S (ed.), Sir John Fortescue: On the Laws and Governance of England, Cambridge, CUO, 1997, págs. 20-21.

${ }^{29}$ Austin, J., The Province of Jurisprudence Determined, Indianapolis, Hackett, 1998 [1832], pág. 198.

${ }^{30}$ Austin, J., op. cit., págs. 152-54. 
implique intención de obedecer. La intención puede ser, en cambio, el fin de evitar algo desagradable (evaluando la probabilidad de detección, y así sucesivamente) o que el sujeto actúe de la forma adecuada sin ningún pensamiento de obediencia. No hay garantías para sostener que el agente desea hacer lo que le es ordenado (porque teme al dolor o busca el auto-interés). En efecto, en la perspectiva de Austin, los actos del soberano de prescribir o proscribir algún acto pueden en algún modo causar que el sujeto actúe de esa manera o meramente coincidir con las acciones del sujeto. Esto se aleja mucho del acto grupal de adoptar y llevar a cabo un tipo de orden. Por ejemplo, en el ejército, cuando un oficial superior elige un plan de acción y ordena a sus subordinados actuar de conformidad, estos adoptan y ejecutan el plan, mostrando externamente la intención de llevarlo adelante para alcanzar el fin compartido de la victoria. Lo que sucede en la acción colectiva del ejército sucede con el derecho, y al describirlo se debe prestar atención a la relación - el patrón de intenciones-que se obtiene entre las personas y su(s) gobernante(s).

Es relevante considerar la distancia que separa a Austin de Hobbes. Para Hobbes, las leyes son las elecciones del soberano que cada sujeto debe adoptar como propias (excepto cuando el soberano ordena su muerte) en aras de la paz y para evitar la auto-contradicción ${ }^{31}$. E1 soberano es capaz de gobernar (es capaz de llevar su voluntad a la práctica) y tiene derecho a hacerlo (de modo que sus súbitos deben obedecerle), porque es constituido por la acción colectiva de sus súbditos. Esto es, la acción colectiva de las personas individuales que, después de eso, son sus súbditos — los miembros de la multitudhace que el soberano exista ${ }^{32}$. Este acto hace de muchos individuos una comunidad política ("Commonwealth"). Los súbditos autorizan al soberano a gobernar, sometiéndose a su voluntad, y el soberano representa la persona artificial del estado que es la comunidad política ("Commonwealth").

${ }^{31}$ Hobbes, T., Leviathan, capítulo 26.

32 Hobbes, T., Leviathan, capítulos 16-18. 
Los miembros de la multitud pactan entre sí, prometen que obedecerán al soberano si los demás hacen lo mismo. En verdad, no tendría sentido autorizar a un gobernante a menos que nuestros vecinos también acuerden elegir a una persona para gobernar. Para Hobbes, la voluntad de la mayoría es suficiente para crear una comunidad política ("Commonwealth"), que incluye a la minoría; entiende que todos tienen la intención de que gobierne quien sea autorizado por la mayoría ${ }^{33}$. Que el soberano sea nuestra creación, que cada uno de nosotros haya querido que actuara, y que lo hiciéramos conjuntamente hace que, dice Hobbes, seamos los autores de sus actos. En consecuencia, no tenemos acción racional aparte de obedecer su voluntad, ya que de otra forma abrazaríamos una auto-contradicción y el probable riesgo de muerte mediante ejecución o guerra civil. Por esto, Hobbes explica la autoridad del soberano y la normatividad del derecho argumentando que el gobierno actual del soberano es nuestra continua acción colectiva. Cualquiera sea su debilidad, y hay muchas, esta teoría es manifiestamente superior a la de Austin enunciada previamente.

Puede verse una línea similar de argumentos en Locke y Rousseau, aunque con diferentes explicaciones de la naturaleza del agente que es la comunidad política ("Commonwealth"). Para Rousseau, no puede investirse a una persona como soberano ya que el ejercicio de la autoridad soberana es siempre colectivo ${ }^{34}$. Para Locke, lo que creamos colectivamente es una autoridad pública de jurisdicción limitada, representativa y, también, capaz de unirnos en la acción ${ }^{35}$. En contraste, Austin no intenta explicar el ejercicio del gobierno como una acción de grupo: en su explicación, los súbditos simplemente padecen el gobierno del soberano. Es importante notar que los súbditos a veces, y puede que usualmente, padecen pasivamente el gobierno de otros. Sin embargo, una teoría del derecho no debería tomar esto como cierto en todos los casos o, aún más importante, tomar esta posibilidad para determinar o fijar la naturaleza del

${ }^{33}$ Hobbes, T., Leviathan, capítulo 17.

${ }^{34}$ Rousseau, J., The Social Contract, Libro I, capítulos 6-7, Libro II, capítulo 1.

${ }^{35}$ Locke, J., Second Treatise of Government, capítulos 10-11. 
derecho. El caso central del derecho, que debería gozar de prioridad explicativa, es agudamente diferente.

\section{IV}

En el Postscript, Hart establece que la aceptación de una regla social consiste en la disposición continua de los individuos de considerar ciertos patrones de conducta como guías para ellos mismos, y como estándares de crítica a otros ${ }^{36}$. Bernal toma este pasaje y medita sobre la naturaleza de una disposición continua ${ }^{37}$. Considera la visión de Shapiro, en la que la disposición es la intención de conformarse y de criticar a otros por su no conformidad ${ }^{38}$. Bernal rechaza esa idea -al menos como explicación general de la aceptación de reglas- y razona que

parece intelectualizar demasiado lo que Hart tenía en mente. La interpretación de Shapiro atribuye a los agentes un consciencia interna con relación a las reglas que va más allá de la que en realidad puede existir. Contrario a lo que Shapiro parece sugerir, es posible pensar que los destinatarios del derecho aceptan las reglas sin siquiera pensar en que en ellos se ha formado la intención de obedecerlas. Hay muchas reglas que regulan la vida social, conforme a las cuales actuamos, y que son el resultado de diversos tipos de presión social. Esta presión social se considera como una forma de entrenamiento, sobre la que todavía no hemos reflexionado. No nos hemos creado sobre ella ninguna representación en nuestra mente, si la hemos articulado explícitamente. Antes bien, lo que acontece es que, en diversas circunstancias, hemos formado hábitos de comportamiento que crean la disposición a asumir dichos comportamientos como patrones que regulan conductas futuras -como si tuviéramos en realidad un compromiso

${ }^{36}$ Hart, H. L. A., The Concept of Law, Oxford, Clarendon Press, 1994 [1961], pág. 225.

${ }^{37}$ Bernal Pulido, C., op. cit., pág. 34.

${ }^{38}$ Bernal Pulido, C., op. cit., pág. 35, cita a Shapiro, S., "What is the Internal Point of View?", 75 Fordham Law Review 1163, 2006. 
intencional condicional a seguir las reglas siempre que surjan circunstancias relevantes-. Sin embargo, en realidad no hemos formado en nuestra mente una representación de dichas reglas ni la intención de obedecerlas. Estas reglas forman parte de lo que John Searle ha denominado el trasfondo de la intencionalidad. Dentro de este contexto, este trasfondo expresa la idea de que existe un elemento intencional de aceptación de reglas, a saber, el punto de vista interno, que se expresa en una disposición pero que no involucra un compromiso explícito de adecuar la conducta futura al contenido de la regla ${ }^{39}$

Cito este extenso párrafo porque es la base del próximo argumento de Bernal en el cual, - desarrollando la teoría de Shapiro - sostiene que el derecho es algo que hacemos todos juntos. Sin embargo, su lectura de Hart no es correcta. Si Shapiro intelectualiza demasiado, Bernal hace desaparecer toda intelectualización. Lo que Bernal delinea no es la aceptación de las reglas, ni tampoco una disposición continua. Se puede tener una intención condicional y actuar de conformidad sin mucha auto-conciencia. Pero aun así se debe adoptar algún curso de acción, eligiendo un fin y sus medios: específicamente, uno elige hacer $\mathrm{X}$ cuando o si $\mathrm{Y}$ sucede. Las "presiones sociales... que equivalen a una forma de entrenamiento" solo explican la aceptación de reglas, digo, si llevan a las personas a adoptar la intención relevante (condicional), mostrándoles que así es como se debe actuar. Las presiones sirven para provocar una disposición continua si alientan al agente a responder a las condiciones relevantes actuando según la regla que ya adoptó (eligió). Alternativamente, las presiones sociales simplemente fallan para inculcar la aceptación de reglas; por el contrario, a lo sumo condicionan a las personas a responder sin pensar a cierto estímulo. Esta alternativa, que para mí adopta Bernal (porque deja a un lado las intenciones reales y habla como si existiera una intención condicional), no explica cómo el agente toma la regla como una razón (o, en efecto cómo el agente es un agente), pero en cambio, al igual que Austin, toma la regla como una predicción sobre 
lo que probablemente suceda. Esta lectura es extraña a la teoría de Hart y es una explicación incorrecta de la aceptación de reglas, por lo tanto debe rechazarse.

Cuando se tiene una disposición continua, no se actúa como si tuviera una intención condicional, sino que se tiene una intención condicional. Estas intenciones son diferentes del trasfondo de Searle, que es lo que se da por sentado al formar intenciones, al entender el mundo (social). El trasfondo no es un 'adopción' irreflexiva de normas particulares y proposiciones, las cuales no serían entonces, en lo absoluto, adoptadas. La palabra disposición puede haber desorientado a Bernal: mientras que, como muchas otras palabras, tiene varios sentidos y puede ser usada para expresar una variedad de significados intencionados, en este contexto debe ser entendida plausiblemente, como lo hace Shapiro (por una buena razón), como intención condicional.

Mientras Hart, al centrarse en la aceptación, es más prometedor que Austin y su hábito de obediencia, Bernal argumenta que para ambos la aceptación de reglas puede ser entendida como una serie de actos individuales o como un acto colectivo ${ }^{40}$. Para Bernal, la primera es una lectura plausible porque el individuo puede él solo mantener la disposición a tomar ciertas reglas sociales como patrones para sí mismo y para toda la sociedad. Para que la aceptación de reglas sea un acto colectivo es necesario que los funcionarios formen actitudes colectivas y entiendan las reglas que gobiernan la acción colectiva. Bernal argumenta que no es claro qué lectura es la mejor, lo que significa, por lo menos, que la teoría de Hart es, como la de Austin, consistente con la visión individual (distributiva) ${ }^{41}$.

No estoy de acuerdo con que la lectura individual sea posible. La preocupación de Hart es sobre las reglas sociales, aceptadas por el grupo para el grupo. Las reglas son reglas sociales porque gobiernan un grupo, en el que cada persona -siendo un miembro del grupo y aceptante de la regla- espera y critica la conformidad de otros, porque

${ }^{40}$ Bernal Pulido, C., op. cit., pág. 37.

41 Ibidem. 
pertenecen al grupo en cuestión. Bernal anticipa este argumento, diciendo que "el establecer un estándar dirigido a todo el grupo social no depende de actitudes sociales comunes necesariamente relacionadas con la lectura colectiva. El soberano de Austin establece también sus mandatos como estándares dirigidos a todo el grupo social" ${ }^{\prime 2}$. Sin embargo, la explicación de Hart de cómo los miembros de una comunidad razonan y actúan es agudamente diferente a la de Austin, que no tiene nada que decir sobre la forma en que cada sujeto se posiciona en relación a otros sujetos: para él, lo único importante era la relación soberano-súbdito. En la versión de Hart, el grupo existe con independencia de la sujeción común a un soberano, siendo las reglas del grupo aquellas que sus miembros aceptan y, por ello, las que aceptan para determinar cuáles son sus reglas. La identidad del grupo, como el conjunto de personas que viven juntas bajo reglas compartidas, es importante para el razonamiento de cada miembro del mismo. Hart da por sentado que el grupo existe en parte porque sus miembros aceptan varias reglas sociales, que son unificadas solo por el hecho de que cada una es una regla aceptada por y para ese grupo ${ }^{43}$.

Que las reglas son las reglas de un grupo en cuanto tal (en vez de conjunto de individuos) es confirmado por la presuposición de Hart de que estas se hacen cumplir por la presión colectiva: cada uno se apoya en los demás para mantenerlas ${ }^{44}$. La gran insuficiencia de apoyarse en una presión informal -relativamente incoordinada- justifica introducir una regla de adjudicación, y esta necesidad, como las otras necesidades que requieren de otras reglas secundarias, sugiere que para Hart las reglas proto-jurídicas del grupo, sus reglas secundarias, son producto de la acción colectiva ${ }^{45}$. La fusión parcial de Hart entre moralidad y reglas sociales oscurece este punto, y dado que plausiblemente puede entenderse la moral convencional como la superposición de juicios morales individuales, se podría pensar que esto se mantiene para otras reglas sociales. Pero la explicación reduccionista de Hart

${ }^{42}$ Bernal Pulido, C., op. cit., pág. 39

${ }^{43}$ Hart, H. L. A., op. cit., pág. 92.

${ }^{44}$ Hart, H. L. A., op. cit., págs. 86-7, 93-4.

${ }^{45}$ Hart, H. L. A., op. cit., págs. 93-7. 
sobre la moralidad, mientras que falsa como tal, confirma que él veía a las reglas sociales como los actos de un grupo, adoptadas por todos como grupo. Esto no quiere decir que explique la estructura de las intenciones entrelazadas que hacen a la acción colectiva posible, pero implica rechazar, sugiero, la idea de que la explicación de las reglas sociales de Hart no involucra la acción colectiva.

Como con otras reglas sociales -sostiene Bernal- la aceptación por parte de los funcionarios de la regla de reconocimiento puede ser individual antes que colectiva. Entonces, cada funcionario puede individualmente aceptar que "lo que la reina establece en el Parlamento es el derecho", sin que colectivamente los funcionarios acepten esta regla ${ }^{46}$. Pero, otra vez, la regla en cuestión concierne a cómo otros deben actuar, no solo la persona que la acepta. ¿Tendría sentido para una persona aceptar esta regla con independencia de la intención de otros? Sería sorprendente, porque el punto de la regla es proveer una regla para el grupo, de modo que es muy importante que todos (o la mayoría) acepten la misma regla. Se podría imaginar una regla de reconocimiento aceptada por una persona con independencia de las intenciones de los demás si la regla pensada funcionara para no dejar las cosas libradas a la propia elección, como los deberes religiosos. Puede ser un ejemplo de esta regla las escrituras del profeta que establecen lo que debe hacerse, y cada persona en el tiempo y lugar pertinentes piensa que debe obedecer, y así lo hace. Aquí, los hechos sociales pueden ser que cada persona acepte la regla pertinente, en lugar de que el grupo lo haga, aunque, aun aquí, puede ser totalmente posible (hasta probable) que las personas pluralmente tengan como objetivo conjunto adoptar la regla — porque sería mejor si nuestra nación, digamos, cumpliera sus obligaciones religiosas y/o porque reconocemos que es vital la coordinación en una formulación similar de reglas.

Igualmente, en ausencia de una comunidad política claramente demarcada y/o cuando emerge un tiempo de anarquía o guerra civil, la coordinación de las personas alrededor de cierta autoridad puede, en un comienzo, ser individual, a saber, elegida con independencia 
del juicio de que los demás harán lo mismo, de modo que actuaríamos colectivamente. Sin embargo, el mismo hecho de apoyar a una persona o a un órgano para gobernar puede ser entendido como una invitación a la acción colectiva, se adopta una regla orientada a toda la comunidad política (las elecciones de esta persona u órgano deben adoptarse como propias) y se muestran a otros los resultados de la cooperación por mantener esa regla a lo largo del tiempo ${ }^{47}$. Este puede ser un caso no-central de acción colectiva, sin lo rico y completo de otros casos, pero apunta a lo que es necesario: la acción colectiva de reconocer alguna autoridad. Una vez que los tiempos problemáticos pasan, hacer previsiones para la acción de ese grupo es una tarea urgente, porque establecer colectivamente la autoridad de alguien en cuanto a grupo ayuda a asegurar un gobierno legítimo.

¿Quién acepta la regla de reconocimiento? Bernal sostiene que para Hart los ciudadanos pueden 'aceptar pasivamente' las acciones de los funcionarios, pero esto no sería necesario, ya que lo que importa es solo la aceptación de los funcionarios. Esta forma de entender a Hart no es del todo exacta. Hart deja en claro que en muchos sistemas jurídicos los ciudadanos aceptan la regla de reconocimiento, y él no sugiere que esto sea pasivo o de algún modo insignificante. La afirmación de que un sistema jurídico puede existir aun cuando solo los funcionarios acepten (además de que los ciudadanos generalmente obedezcan - esto es, se conformen con - las reglas primarias) no significa, como Bernal asume, que la aceptación de los ciudadanos no tenga importancia o sea superflua. Aun así, Hart es claro cuando sostiene que un sistema jurídico puede existir sin la aceptación de los ciudadanos $^{48}$. Bernal argumenta que esta asimetría entre ciudadanos y funcionarios significa que la explicación de Hart del derecho es la de una práctica de funcionarios, no una práctica social ${ }^{49}$. (Considero que sería mejor afirmar que en la explicación de Hart el derecho, a veces,

${ }^{47}$ Ekins, R., "How to be a Free People", American Journal of Jurisprudence, 58, 2 (en preparación), sección III, "The Unity of the People", y sección IV, "Authority and Agency", 2013.

${ }^{48}$ Hart, H.L.A., op. cit., págs. 116-17.

${ }^{49}$ Bernal Pulido, C., op. cit. 
es solamente una práctica oficial, porque, claro está, en algunos casos los ciudadanos sí aceptan la regla de reconocimiento). Esta asimetría es útil, Bernal sostiene, pero falla para explicar cómo la práctica de las autoridades oficiales es capaz de crear reglas que son jurídicamente vinculantes para todos. En efecto, esta asimetría parece poner a Hart en línea con Austin sobre este punto, incapaz de explicar por qué los ciudadanos están obligados a obedecer el derecho. Además -Bernal continúa- Hart no puede explicar siquiera por qué los funcionarios que aceptan la regla de reconocimiento deberían obedecerla. No estoy seguro si Hart se molestaría con esta objeción, ya que él busca, conjeturo, capturar el hecho social de que alguien toma la regla como una razón, pero no busca él mismo explicar esta razón. Sin embargo, estoy de acuerdo totalmente con Bernal en que uno no debe quedarse aquí, y que, en efecto, hay mucho en la argumentación de Hart que sugiere y toma ventajas de esa explicación.

Imagine que solo los funcionarios aceptaran la regla de reconocimiento. Esto significaría que los ciudadanos serían en algún sentido los objetos sin voluntad del sistema jurídico, en lugar de sujetos con voluntad. Este estado de cosas es sin duda posible y significaría que los ciudadanos no piensan que están obligados a obedecer el derecho: estas actitudes serían hechos sociales. Los funcionarios podrían seguir pensando que los ciudadanos están obligados a obedecer el derecho y que los ciudadanos deberían pensar que lo están, lo que confirmaría que los funcionarios aceptan la regla de reconocimiento no como miembros del grupo 'funcionarios', sino como miembros de la sociedad en su conjunto. De otra forma, los funcionarios podrían pensar que los ciudadanos son el objeto sobre el que hay que actuar, dominar, explotar, gestionar, y así sucesivamente. Cualquiera de los estados de cosas es posible y ambos surgen del caso central del derecho, el segundo de forma más radical que el primero. En estos actos sociales -acuerdos entre las personas, incluyendo funcionarios y ciudadanos- falta lo que distingue al caso bien formado, que justifica que este sea introducido y mantenido, esto es, la acción compartida de todos a través de algunos estándares públicos adoptados como razones para la acción. 
En la segunda parte de su artículo, Bernal, con una mirada favorable, analiza la teoría de Shapiro ${ }^{50}$, para reforzarla frente a críticas recientes. Shapiro argumenta que el sistema jurídico es un conjunto complejo de planes unificados por un plan maestro que es la regla de reconocimiento. Los funcionarios aceptan el plan maestro y la normatividad del derecho se sigue de la racionalidad instrumental: esto es, habiendo adoptado un plan los funcionarios deben llevarlo a cabo. Bernal delinea la teoría de la planificación de Shapiro con detalle, argumentando que "La teoría del derecho como un plan es, sin lugar a dudas, la postura más desarrollada del derecho como práctica social" ${ }^{\prime 1}$. Argumenta que, en contraste con Austin y Hart, la idea de compartir un plan es totalmente colectiva y no deja lugar a una lectura distributiva. La virtud del enfoque de Shapiro, dice, es que "compartir un plan es algo que los miembros de un grupo solo pueden hacer juntos" ${ }^{2}$, el plan es de conocimiento común, y al compartirlo los miembros del grupo deben tener la actitud común [we-attitude] de aceptarlo.

No estoy seguro de que la propuesta de Shapiro de un plan compartido explique correctamente la acción colectiva. Al desarrollar la agencia compartida, Shapiro piensa que es vital (siguiendo a Kutz) dar cuenta de la realidad de que muchas personas son indiferentes al éxito de la actividad compartida ${ }^{53}$. Él afirma que es algo conocido sobre el derecho que algunos funcionarios se encuentran alienados de sus trabajos, y que este tipo de cosas son las que la teoría del derecho debe explicar ${ }^{54}$. Shapiro vuelve con frecuencia al tema de la

${ }^{50}$ Bernal Pulido, C., op. cit., págs. 46 y ss.

${ }^{51}$ Bernal Pulido, C., op. cit., pág. 60.

52 Ibídem.

${ }^{53}$ Shapiro, S., op. cit., pág. 418, n13, citando Kutz, C., Complicity: Ethics and Law for a Collective Age, Cambridge, CUP, 2000, págs. 96-103.

54 Shapiro, S., op. cit., pág. 15; esta es una forma extraña, y no ayuda a entender el método de la teoría del derecho. Sobre esto ver Köpcke Tinturé, M., "Positive Law's Moral Purpose(s): Towards a New Consensus?", American Journal of Jurisprudence, 56, 2011, pág. 210-11. 
alienación ${ }^{55}$, que define, en efecto, como la falta de intención en el éxito del proyecto. Sería mejor decir que los participantes alienados no tienen intención en alcanzar los fines del plan y actúan, en cambio, para lograr fines personales adoptando, todos o parte de, los medios del grupo como propios.

Es verdad, sostengo, que hay participantes que en algunas acciones colectivas no tienen intención de alcanzar los fines para los cuales el plan es un medio. Esta forma de participación, que puede ser común, se aleja en un sentido importante del caso central de la acción colectiva en el que las personas buscan alcanzar un fin conjuntamente. La acción colectiva puede involucrar participantes alienados, pero la forma de entender esta acción es centrándose en los participantes que están comprometidos, que tienen intención de alcanzar los fines para los que actúa el grupo. Esos fines se explicitan en la propuesta (a veces compleja) de acción que se hace a los participantes, la cual consiste en adoptar determinados medios para alcanzar algunos fines. Se entiende a la acción colectiva en general como un reflejo de la acción colectiva que es la ejecución de medios para fines verdaderamente compartidos; $y$, a su vez, se entiende a una acción colectiva en particular como el reflejo de una propuesta que se le da a los miembros de un grupo, y a través del análisis del sentido con el cual las personas la adoptan, si fuera el caso.

Mi preocupación con la teoría de Shapiro no es que él note la posibilidad de alienación, sino que no ve claramente que el participante comprometido auto-consciente tiene una prioridad explicativa al pensar en la acción colectiva. No diferenciar entre quienes se encuentran alienados y quienes están comprometidos puede, sugiero, hacernos perder de vista la realidad social de la acción colectiva. Consideremos el ejemplo de Shapiro en el que Dudley y Stephens comparten un plan:

...el compartir un plan no implica que los miembros del grupo deseen o tengan la intención de que el plan funcione.

${ }^{55}$ Shapiro, S., op. cit., págs. 97, 108-10, 144-6, 150, 175, 204, 207, 216, 413 n30, 418 n13. 
Digamos que quiero que mi casa sea pintada y contrato a mis dos enemigos jurados, Dudley y Stephens, para pintarla. Le ofrezco \$1000 dólares [sic] a Dudley si él hace lo que yo le digo que haga. Le ofrezco a Stephens las mismas condiciones. Ambos aceptan porque necesitan el dinero. Luego le digo a Dudley que lije toda la pintura vieja y a Stephens que pinte una nueva capa sobre la superficie lijada. A pesar del hecho de que Dudley y Stephens me odian, detestan la idea de que mi casa esté recién pintada, y, por lo tanto, no tienen la intención de que la casa sea pintada, sin embargo comparten el plan de que Dudley lije y Stephens pinte. Ellos comparten el plan que yo diseñé para ellos, les es accesible y lo aceptaron ${ }^{56}$

Yo niego que Dudley y Stephens compartan el plan. Sus acciones individuales pueden estar coordinadas por Shapiro, quien los controla, pero ellos no actúan conjuntamente. Shapiro diseña un plan en el que prevé que cada hombre tenga un rol, pero ellos no aceptan el plan. Cada hombre está dispuesto a hacer lo que Shapiro les diga. Esa voluntad de ningún modo implica aceptar un plan con otros. Sería bastante diferente si los dos hombres fueran contratados conjuntamente: 'les pagaré $\$ 1000$ a cada uno, si trabajan en conjunto como yo les diga'. Tomar el dinero de Shapiro podría llevar a la acción colectiva si este dirigiese a ambos hombres para que cada uno entrelace intenciones con el otro para pintar la casa juntos.

Pero, a menos que se formen esas intenciones, no habría acción colectiva. Shapiro parece mezclar aquí el deseo con la intención e ignorar la forma en que un plan es una intención. Stephens podría no desear que mi casa esté recién pintada y aún así tener la intención de pintarla, porque quiere ganar su pago: en efecto, el ejemplo sugiere que esto es exactamente lo que él hace. Dudley no pinta la casa, pero lleva a cabo una acción que permitirá que otro la pinte. Shapiro tiene un plan según el cual actúa, que implica dirigir a estos dos hombres a hacer determinadas acciones. No se sigue de esto que los dos hombres compartan un plan. 
En ese sentido Margaret Gilbert tiene razón: ellos pintan la casa entre los dos pero no de forma conjunta ${ }^{57}$. O en otras palabras, la combinación de sus acciones intencionales puede ocasionar un cierto estado de cosas y, aún así, los sujetos no comparten o llevan a cabo un plan para este efecto. La búsqueda del menor común denominador, el modo de participación más simple en la acción colectiva, lleva a Shapiro por mal camino. El ejemplo de Dudley y Stephens falla porque no hay nada en el ejemplo que sugiera que los dos hombres cooperaron siquiera. En efecto, como se lo presenta, el ejemplo es similar al de Bratman en el que dos hombres pintan una casa de manera independiente (con conocimiento común), donde uno pinta sobre el trabajo del otro ${ }^{58}$.

La participación alienada en la acción colectiva implica una intención de adoptar en parte el plan de la acción colectiva que se les presenta a todos los miembros. Este tipo no central de participación puede tomar muchas formas. Puede ser muy significativo que algunos miembros de un grupo con una intención no estén comprometidos. Un ejército de conscriptos relativamente comprometidos puede ser un grupo con una intención que adopta el plan compartido de la cadena de mandos y las órdenes particulares permaneciendo indiferentes en gran medida al objetivo de la victoria. Este grupo se diferencia del de los soldados voluntarios comprometidos, quienes adoptan el plan con la intención de seguir los medios para alcanzar el fin compartido. El primero no puede entenderse en referencia al segundo, ambos exponen realidades sociales relacionadas pero diferentes, que justifican distintas elecciones de parte de los funcionarios $\mathrm{u}$ otros.

Lo que dice Shapiro sobre los funcionarios alienados que comparten un plan no encuadra en la acción colectiva. Como con Dudley y Stephens, los funcionarios no necesitan actuar conjuntamente con la intención de participar en la acción de un grupo para lograr un fin común. Sus acciones individuales pueden ser arregladas

${ }^{57}$ Shapiro, S., op. cit., pág. 418 n13; Shapiro expresa que Gilbert le dijo esto una vez.

${ }^{58}$ Bratman, M., Faces of Intention, Cambridge, Cambridge UP, 1999, págs. 109-29. 
por un controlador cuidadoso para causar cierto estado de cosas, pero esas acciones no constituyen una acción colectiva a menos que las personas en cuestión tengan la intención, en alguna medida, de actuar juntas. El soberano de Austin podría ser ese controlador, que aterroriza a cada persona para que haga lo que él ordena, de forma que los actos individuales son organizados por el gobernante.

El camino para entender una realidad social es atender a los razonamientos y elecciones de las personas cuyas acciones constituyen la realidad en cuestión ${ }^{59}$. Al explicar un tipo general de práctica social, el teórico debe dar prioridad explicativa a las buenas razones, a las elecciones bien formadas, que señalan cuál es el caso central que ayuda a ver los particulares -el sin fin de tipos de hechos sociales- en una relación inteligente entre ellos. Esto no es solo un pensamiento deseado, sino una respuesta inteligente a la naturaleza de los hechos sociales, en todo coherente con ver claramente lo que es y lo que no es. No querer explorar con cuidado las buenas razones que hay para la acción y la búsqueda de un mínimo común denominador explica el énfasis que Shapiro pone en la perspectiva del participante alienado y su disposición a limitar arbitrariamente las preguntas sobre las razones para el derecho. Se ve esta mezcla de problemas en su discusión sobre su tesis respecto al objetivo moral del derecho, que sostiene: "el objetivo fundamental de la actividad legal es remediar las deficiencias morales de las circunstancias de la legalidad"60.

Shapiro argumenta que "el derecho tiene un objetivo independiente del que tienen los participantes jurídicos" 61 . Esta es una verdad conceptual y, también, una verdad esencial sobre la actividad jurídica. Esta, según él supone, debe solucionar problemas morales, aún si los funcionarios "solo fingen perseguir objetivos nobles" mientras que en realidad actúan solo "para su propia ganancia material"62. Por esto, no es que los funcionarios deban "al menos al final hacer como que persiguen nobles fines", ya que muchos funcionarios pueden estar

\footnotetext{
${ }^{59}$ Finnis, J., Natural Law and Natural Rights, op. cit., capítulo I.

${ }^{60}$ Shapiro, S., op. cit., pág. 213.

${ }^{61}$ Shapiro, S., op. cit., pág. 216.

${ }^{62}$ Shapiro, S., op. cit.
} 
alienados $^{63}$. Él sostiene, en cambio, en un pasaje que Bernal cita en extenso, que

el derecho tiene el fin que tiene porque los funcionarios de alto rango representan la práctica como si tuviera un fin o fines morales. Sus declaraciones no necesitan ser sinceras, pero deben ser hechas. ${ }^{64}(\ldots)$ Ellos describen [la actividad jurídica], en otras palabras, como una actividad que se supone debe solucionar problemas morales y por esa razón [el derecho] debe ser obedecido. ${ }^{65}$

Los funcionarios de rango más bajo, continúa Shapiro, deben al menos "usar el lenguaje moral para describir el derecho" pero esto "no significa que ellos personalmente aprueben, o estén tratando de hacer que otros piensen que personalmente aprueban esas evaluaciones morales" 66 .

Por mi parte, parece como si todos -altos y bajos- deban fingir al menos un poco, aunque no necesiten ser convincentes. Shapiro observa la pregunta retórica de Agustín: “¿Sin justicia qué son los reinos más que grandes bandas de ladrones?" 67 . Su respuesta es que moralmente nada los distingue, pero conceptualmente la apariencia es muy importante ${ }^{68}$. Este es un análisis desconcertante y contrasta con lo que Agustín continúa diciendo:

¿Y qué es una banda de ladrones si no un reino en miniatura? Es una banda de hombres bajo el gobierno de un líder, unidos por un pacto de amistad, y su botín es dividido entre ellos por una regla acordada. Esta mancha en la sociedad, si crece, asume para sí el orgulloso nombre de reino.

${ }^{63}$ Shapiro, S., op. cit.

${ }^{64}$ Shapiro, S., op. cit., pág. 216-17; para una crítica incisiva ver Köpcke Tinturé, M., op. cit., 186-7.

${ }^{65}$ Shapiro, S., op. cit., pág. 217.

${ }^{66}$ Shapiro, S., op. cit.

${ }^{67}$ Augustine, City of God, IV, 4.

${ }^{68}$ Shapiro, S., op. cit., pág. 217. 
La banda de ladrones es un reino injusto en miniatura y un reino injusto es una banda de ladrones que creció en extremo, precisamente porque los fines de la acción colectiva en cada uno son los mismos. La práctica del derecho es pensada plausiblemente como una acción colectiva. Los fines de cada acción colectiva en particular son los fines de las personas que actúan conjuntamente, a saber, los fines compartidos que tienen como objetivo realizar. El funcionario alienado no es de ayuda para elegir esos fines porque, por hipótesis, él participa de a ratos de forma incompleta en la acción colectiva en cuestión. La perspectiva del funcionario comprometido es de más ayuda, pero aquí son los objetivos reales los que importan, porque son los hechos sociales relevantes. En verdad, la razón de ser del derecho, considerado como un tipo de práctica, una continua posibilidad para la acción inteligente (colectiva), es garantizar el bien común. No es verdad que el objetivo de cada regla en particular o sistema jurídico sea este. El fin de un sistema de reglas dado a conocer en la acción colectiva, como reglas en el razonamiento y elección de personas, puede ser precisamente extraer las riquezas de sus víctimas. Es interesante que algunas bandas de ladrones elijan aparentar que sirven al bien común. Pero esta apariencia no hace que el objetivo de su acción conjunta injusta sea remediar las deficiencias morales de las circunstancias de la legalidad.

Me parece que Shapiro ve, para darle crédito, que el derecho tiene un propósito moral, pero cuya verdadera naturaleza no quiere desente$\operatorname{rrar}^{69}$, y en cambio se refugia en un análisis confuso de las intenciones de los funcionarios, que confunde los hechos sociales relevantes. Así, no atiende lo suficientemente de cerca a las buenas razones que hacen del derecho una forma social distinta, en condiciones de ser elegido, o los hechos sociales en los que en parte consiste. Esta falta de atención a ambas cosas, a las razones y a los hechos sociales, está también en el trabajo de Shapiro sobre la discusión respecto a la acción institucional (o como él lo llama 'actividad'; la diferencia de sentido es reveladora). Argumenta que las legislaturas, por ejemplo,

${ }^{69}$ Köpcke Tinturé, M., op. cit., pág. 184-9. 
no necesitan formar intenciones para promulgar legislación, solo necesitan seguir los procedimientos establecidos por el plan maestro. La estructura del plan maestro, explica, hace a la normatividad del derecho institucional, "lo que quiere decir que las relaciones jurídicas pueden obtenerse entre personas independientemente de la particular intención de estas personas"70.

El análisis de la producción legislativa de Shapiro no es más sólido que el de Max Radin, y no es fiel al razonamiento y a la elección que hacen los legisladores, especialmente los legisladores razonables ${ }^{71}$. Al respecto, resulta de importancia el hecho de que Shapiro esté bastante equivocado al entender las instituciones como sitios en los que es posible la actividad sin intención, y sostenga que el punto de la regla de reconocimiento es, en parte, convertir a las intenciones reales en irrelevantes. Instituciones tales como el Parlamento del Reino Unido o el Municipio de la Ciudad de Oxford son agentes capaces de agencia racional a lo largo del tiempo. El agente no es ninguno de los miembros del grupo con una intención en particular, estos forman (dan vida) a la institución en cualquier tiempo, pero es su capacidad de acción la que da lugar a la acción colectiva. El sistema jurídico puede, por una buena razón, excluir las disputas sobre la intencionalidad de la acción institucional en cuestión, pero de esto no se sigue que la acción no implique intención (lo hace, al menos en cualquier acto bien formado, a saber las intenciones de la institución y las intenciones de los miembros) o que la relación relevante (¿resultante?) entre personas no involucre intenciones. Por el contrario, al reconocer la autoridad de la legislatura, los sujetos del derecho buscan identificar y hacer efectiva la intención promulgada (elección) que es su ejercicio. Así, lo que Bernal toma como mérito de la teoría de Shapiro ${ }^{72}$ - que explica cómo la práctica legal es institucional, de modo que las actuales intenciones son a menudo irrelevantes - es en realidad un defecto.

${ }^{70}$ Shapiro, S., op. cit., pág. 210.

${ }^{71}$ Radin, M., "Statutory Interpretation", Harvard Law Review, 43, 1929-1930, pág. 871.

$138 \quad{ }^{72}$ Bernal Pulido, C., op. cit. 


\section{VI}

La objeción principal de Bernal a la teoría de Shapiro es el argumento de Celano. Esto es que Shapiro ilegítimamente concluye, a partir de la normatividad, que un plan tiene para el individuo que lo adopta para sí mismo, que el plan adoptado para otros también es capaz de obligar. ${ }^{73}$ Bernal expone la respuesta de Shapiro, según la cual esta es una visión extremadamente reducida de los planes, por centrarse solo en el rol normativo de los planes en la agencia individual e ignorar "su aspecto tecnológico"74. Esta no es una muy buena respuesta, pero me pregunto si Shapiro no debería admitir que la aceptación de los funcionarios de un plan no hace que sea racional para los ciudadanos llevar adelante el plan. Su interés, me parece, está en la forma en que los funcionarios piensan y actúan. Los funcionarios deben aplicar, y de hecho lo hacen, el plan a los ciudadanos a pesar de que estos no lo acepten, no lo compartan: el punto de vista jurídico es el punto de vista de los funcionarios. Su discurso y sus actos son hechos como si el plan vinculara a los ciudadanos (y, algunas veces, los funcionarios hasta son sinceros). Mientras que no tienen que aceptar la legitimidad del derecho, los ciudadanos deben generalmente obedecer (conformarse a) lo que determinan los funcionarios ${ }^{75}$. Bernal nota que la objeción de Celano a Shapiro es similar a la propia objeción de Bernal a Hart, a saber, que su teoría explica el derecho solo como una práctica de funcionarios en vez de una práctica social ${ }^{76}$.

No pienso, repito, que el objetivo de Shapiro sea explicar cómo el derecho es vinculante normativamente para los ciudadanos. Él sigue a Hart, me parece, al pensar que para que exista un sistema jurídico todo lo que los ciudadanos necesitan hacer es conformarse. Aun así, la principal contribución del artículo de Bernal es delinear un

${ }^{73}$ Bernal Pulido, cita a Celano, B., "What can Plans do for Legal Theory?

" en Canale, D., y Tuzet, G., (eds), The Planning Theory of Law, London, Springer, 2013, pág. 129.

${ }^{74}$ Bernal Pulido, C., op. cit. pág. 65.

${ }^{75}$ Shapiro, S., op. cit., pág. 202.

${ }^{76}$ Bernal Pulido, C., op. cit. 
argumento en la misma línea de Legality, que considera que Shapiro debería adoptar para explicar por qué el derecho es normativo para los ciudadanos. La forma general del argumento sugiere que los ciudadanos aceptan el plan de ser deferentes al plan de otro, es decir, aceptan el plan maestro. Sin embargo:

Asumir que todos los sujetos del derecho despliegan una actividad intencional consistente en adoptar el plan maestro es inseguro. No existe un solo país en el que la redacción de una constitución sea el resultado de una acción intencional colectiva en la que todos los sujetos del derecho participen de hecho activamente con sus intenciones comunes y sus acciones, en forma de una acción grupal. Y Shapiro, de hecho, no asume esto. Sostiene en cambio que solo las autoridades oficiales son miembros del grupo que debe adoptar el plan maestro ${ }^{77}$.

A continuación Bernal se pregunta si solo cuando los funcionarios aceptan el plan maestro es posible que la autoridad exista, que el derecho sea normativo. La respuesta de Shapiro, me imagino, es que la autoridad debe entenderse desde la perspectiva jurídica, como un funcionario la vería.

Los ciudadanos pueden experimentar el derecho como una opresión. Esto es verdad a veces, pero no siempre. Existiría un problema si Shapiro fuera incapaz de explicar la diferencia en uno y otro caso, como sí lo hace Hart. Bernal cita a Shapiro cuando este recurre al ejemplo de las Islas Cook $^{78}$, en el cual se dice que los habitantes de las islas aceptan el plan maestro porque piensan que los planificadores son moralmente legítimos. Este requisito, dice Bernal, sería muy exigente para las extensas sociedades modernas, por lo que Shapiro lo menciona solo como una posibilidad. En cambio, continúa Bernal, Shapiro da a entender que la normatividad del derecho depende de la disposición de los ciudadanos a seguir los planes reconocidos por el plan maestro, y del hecho de que los

77 Bernal Pulido, C., op. cit., págs. 66-67.

$140 \quad{ }^{78}$ Bernal Pulido, C., op. cit., pág. 165 cita a Shapiro. 
ciudadanos normalmente obedezcan a aquellos que están autorizados $^{79}$. Bernal interpreta que esto equivale a "una aceptación tácita del plan maestro... basado en actividades colectivas intencionales y no intencionales." Considero que Bernal ha entendido mal a Shapiro, quien al referirse a la obediencia a aquellos que son autorizados, quiere expresar la condición de eficacia; esto es, que los ciudadanos de hecho obedezcan.

De cualquier modo, el argumento de Bernal para las actividades colectivas no intencionales está mal concebido. Que nosotros contaminemos el ambiente de forma no intencional no es, ni remotamente, análogo a aceptar el sistema jurídico. Su análisis de la disposición continua de Hart, que critiqué arriba, no puede soportar el peso del argumento. Es plausible pensar que la práctica jurídica es, en el caso bien formado, la acción colectiva de ciudadanos y funcionarios. Sin embargo, esto es severamente diferente a decir que la práctica jurídica es la acción colectiva intencional de los funcionarios, que son empoderados (un término bastante incierto en este contexto) para actuar por los ciudadanos; los que, a su vez, actúan todos juntos, algunos de forma intencional y otros no intencional. Este actuar 'todos juntos' es un espejismo porque simplemente no es verdad que conjuntamente contaminemos el ambiente. Por eso, es cierto que si no actuamos todos intencionalmente, no aceptamos conjuntamente la acción de los funcionarios en cuestión.

\section{VII}

Afirmaciones sobre obviedades estropean el trabajo de Shapiro. De la misma forma, Bernal incorrectamente da por sentado la normatividad del derecho. Los hechos sociales que para Austin estaban presentes siempre, pueden estarlo a veces; y puede haber (otras) instancias del 'derecho' en las que sean los funcionarios quienes actúen conjuntamente, en lugar de hacerlo los ciudadanos. Estas posibilidades no deben ser ignoradas, pero tampoco deben distorsionar la teoría del

${ }^{79}$ Bernal Pulido, C., op. cit., pág. 68, cita a Shapiro, 179-80. 
derecho: esto es, requieren de una cuidadosa explicación. La manera de dar sentido a esta variedad de posibilidades es adoptar la perspectiva de una persona razonable, y tomar las buenas razones que hay para elegir, introducir y mantener una forma social distinta. E1 caso central del derecho, pienso, implica la acción colectiva de los miembros de la comunidad política, quienes forman y mantienen las autoridades públicas que aseguran el bien común. Por esto, en un sistema jurídico bien formado las autoridades eligen planes para la acción que son medios inteligentes para el bien común, los cuales se espera que sean, y de hecho son, adoptados por los ciudadanos como su propia elección ${ }^{80}$. De este modo, la autoridad razonable invita a los ciudadanos a participar en el estado de derecho; la dirección y respuesta razonables constituyen un tipo de autoridad compartida, en la que los sujetos del derecho son participantes voluntarios del proyecto de gobierno. En otros términos, ellos son sujetos en los dos sentidos de la palabra, reconocen y acatan la autoridad, pero también actúan al introducirla (al reconocer a aquellos con capacidad para asegurar el bien común) y mantenerla.

La base ontológica del derecho es nuestra voluntad compartida actual de tomar actos pasados de legislación y adjudicación como buenas razones para fijar lo que debemos hacer ahora ${ }^{81}$. Que nos veamos a nosotros mismos como miembros de una comunidad política, con un bien común por el cual debemos actuar fundamenta esa voluntad. En efecto, la continuidad del derecho a lo largo del tiempo da lugar a la continuidad del grupo con una intención que es nuestra comunidad política ${ }^{82}$. Que formemos parte de ese grupo

${ }^{80}$ Ekins, R., The Nature of Legislative Intent, op. cit., capítulo 5.

${ }^{81}$ Finnis, J., "Reflections and Responses", en George, R. y Keown, J. (eds.), Reason, Morality and Law: The Philosophy of John Finnis, Oxford, Oxford UP, 2013, págs. 459, 519.

82 Ver Ekins, R., "Constitutional Principle in the Laws of the Commonwealth", en George, R. y Keown, J. (eds.), Reason, Morality and Law: The Philosophy of John Finnis, Oxford, Oxford UP, 2011, pág. 396-401, discussing Finnis, J., Philosophy of Law, Collected Essays: Volume IV, OUP, Oxford, ensayo 21 ('Revolutions and Continuity of Law' [1971]), 2011, pág. 407. 
es un hecho social, un hecho sobre nuestras intenciones para con los demás, sobre nuestra disposición a confiar en los demás y a sacrificar mucho el uno por el otro. El grupo de acción relevante es la comunidad política, salvo en casos aberrantes, donde la comunidad no está todavía formada o es de alguna u otra forma totalmente incapaz de acción razonable, en cuyo caso la autoridad puede (y debería) ejercerse aparte de la acción colectiva de todos. Es posible para los funcionarios ejercer la autoridad y cambiar nuestras razones para la acción porque existen buenas razones para que haya autoridad, razones que reconocen los miembros (la mayoría) de una comunidad bien formada. Estos miembros, conjuntamente, toman a los funcionarios como sus representantes para actuar por ellos como grupo, asegurando su bien común, al crear y aplicar el derecho. Así, la acción colectiva, que constituye un sistema jurídico bien formado, es un cierto tipo de hecho social, un hecho social que involucra personas reconociendo razones que como tales son buenas, y por las que los hechos sociales de legislación o adjudicación son capaces de cambiar sus razones para la acción.

\section{Bibliografía}

Aquino, Summa Theologica.

Aquino, Sententia Libri Ethicorum [Commentary on Aristotle's Nichomachean Ethics], Prólogo de Finnis, J., Aquinas: Moral, Political and Legal Theory, Oxford, OPU, 1998.

Augustine, City of God.

Austin, J., The Province of Jurisprudence Determined, Indianapolis, Hackett, 1998 [1832].

Bernal Pulido, C., "Austin, Hart y Shapiro. Tres variaciones alrededor del derecho como una entidad fundada en una práctica social", Discusiones, XIV, 2014. págs. 21-72

Bratman, M., Faces of Intention, Cambridge, Cambridge UP, 1999.

Ekins, R., "ConstitutionalPrincipleintheLaws of the Commonwealth", en George, R. y Keown, J. (eds.): Reason, Morality and Law: The Philosophy of John Finnis. Oxford UP, Oxford, 2011. 
Ekins, R., The Nature of Legislative Intent, Oxford, Oxford UP, 2012.

Ekins, R., "How to be a Free People", American Journal of Jurisprudence, 58, 2, 2013.

Finnis, J., "Prologue: Aquinas: Moral, Political and Legal Theory", en Aquino, Sententia Libri Ethicorum (comentario a la Ética Nicomaquea de Aristóteles), Oxford UP, Oxford, 1998.

Finnis, J., Natural Law and Natural Rights, Oxford-New York, Clarendon Press-Oxford University Press, (2. ${ }^{a}$ ed.), 2011.

Finnis, J., "Reflections and Responses", en George, R. y Keown, J. (eds.), Reason, Morality and Law: The Philosophy of John Finnis. Oxford UP, Oxford, 2013.

Fortescue, J., "In Praise of the Laws of England", chapter XII, en Lockwood, S. (ed.), Sir John Fortescue: On the Laws and Governance of England, Cambridge, Cambridge UP, 1997, págs. 20-21.

Hart, H. L. A., The Concept of Law, Oxford, Clarendon Press, 1994 [1961].

Hobbes, T., Leviathan.

Köpcke Tinturé, M., "Positive Law's Moral Purpose(s): Towards a New Consensus?", American Journal of Jurisprudence, 56, 2011.

List, C. y Pettit, P., Group Agency, Oxford, Oxford UP, 2011.

Locke, J., Second Treatise of Government.

Radin, M., "Statutory Interpretation", Harvard Law Review, 43, 1929-1930.

Rousseau, J., The Social Contract.

Shapiro, S., Legality, Cambridge, Harvard University Press, 2011. 